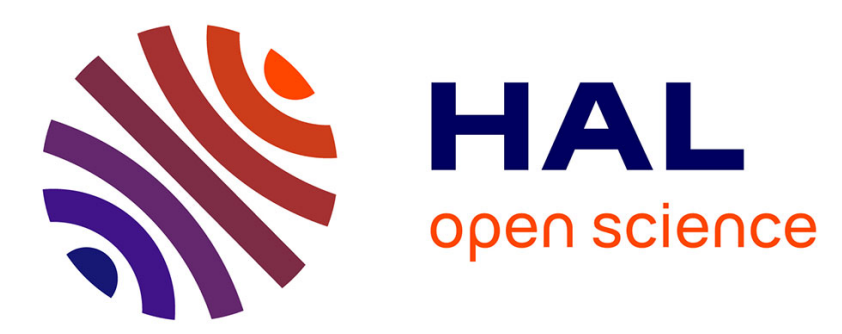

\title{
Water erodible coatings based on a hydrolyzable PDMS/polyester network
}

Laure Gevaux, Marlene Lejars, André Margaillan, Christine Bressy

\section{To cite this version:}

Laure Gevaux, Marlene Lejars, André Margaillan, Christine Bressy. Water erodible coatings based on a hydrolyzable PDMS/polyester network. Materials Today Communications, 2018, 17, pp.517-526. 10.1016/j.mtcomm.2018.10.020 . hal-02432101

\section{HAL Id: hal-02432101 https://hal.science/hal-02432101}

Submitted on 8 Jan 2020

HAL is a multi-disciplinary open access archive for the deposit and dissemination of scientific research documents, whether they are published or not. The documents may come from teaching and research institutions in France or abroad, or from public or private research centers.
L'archive ouverte pluridisciplinaire HAL, est destinée au dépôt et à la diffusion de documents scientifiques de niveau recherche, publiés ou non, émanant des établissements d'enseignement et de recherche français ou étrangers, des laboratoires publics ou privés. 


\title{
Water erodible coatings based on a hydrolyzable PDMS/polyester network
}

Laure Gevaux, ${ }^{\mathrm{a}}$ Marlène Lejars, ${ }^{\mathrm{a}}$ André Margaillan ${ }^{\mathrm{a}}$ and Christine Bressy ${ }^{\mathrm{a}}$

${ }^{a}$ Université de Toulon, MAPIEM, EA 4323, 83957 La Garde, France

\begin{abstract}
In this work, the objective is to design an elastomer network predominantly composed of poly(dimethylsiloxane) (PDMS) with small crosslinked hydrolyzable polyesters to finally provide a new eco-friendly antifouling system. This PDMS/polyester network is expected to maintain a low surface energy during water immersion while, at the same time, ensuring a continuous renewal of its surface through an erosion process. The PDMS/polyester networks were crosslinked via a condensation reaction of a bis-silanol PDMS oil and various bis(trialkoxysilane)-terminated polyester macrocrosslinkers. Chain ends of poly( $\varepsilon$-caprolactone), poly( $\varepsilon$-caprolactone)-b-PDMS- $b$-poly( $\varepsilon$-caprolactone) and poly(D,L-lactideco-glycolide) were quantitatively functionalized using (3-isocyanatopropyl)trimethoxysilane as crosslinking reactant. These polyester macrocrosslinkers were highly inserted in the PDMS-based networks in quantities ranging from 12 to 40 wt.\%. The microtopography of these PDMS/polyester coatings revealed relatively low roughness values for most of the coatings. Contact angle measurements highlighted an increase of hydrophilicity for PCL-based coatings contrary to the poly(D,L-lactide-co-glycolide)-based coating which demonstrated a surface hydrophobicity as well as a low surface free energy $\left(\gamma_{\mathrm{s}} \leq 25 \mathrm{~mJ} / \mathrm{m}^{2}\right)$ even after 5 weeks of immersion in deionized water. The insertion of polyesters within a silicone matrix affected both the elastic modulus and the cristallinity of the network depending on the polyester nature. Finally, mass loss tests demonstrated that these PDMS/polyester coatings had the ability to erode themselves.
\end{abstract}

\section{ARTICLE INFO}

Keywords:

Elastomer network

Poly(dimethylsiloxane)

Hydrolyzable polyester

Erodible coating 


\section{Introduction}

The universal ban of organotin compounds in antifouling coatings in 2008 was a pioneering step in the development of more ecofriendly ship hull paints [1]. The European Biocidal Products Regulation also contributes to limit or even prohibit the leaching of some toxic substances responsible for non-targeted marine species death [2]. Thus, there is a growing interest in developing biocide-free antifouling coatings. Among them, Fouling Release Coatings (FRC), based on poly(dimethylsiloxane) (PDMS) elastomers, exhibit self-cleaning ability while subjected to hydrodynamic forces, provided by their specific properties: low-roughness surfaces, low surface free energy, and low elastic modulus[3]. However, they can be covered by fouling organisms in absence of hydrodynamic shear stress. Some micro-organisms such as diatoms also seem to adhere more severely on these hydrophobic surfaces. Despite these issues, FRC still represent a hopeful solution to substitute the Self-Polishing Coatings (SPC) well-known for their release of highly toxic substances in seawater [4,5]. Therefore, considerable effort is being made to improve the efficacy of the antifouling and fouling release properties of PDMS-based coatings during idle periods. Many researchers like Galli's group and Grunlan's group have focused their research on the addition of small amounts of amphiphilic surface-active (co)polymers ( $<10 \mathrm{wt}$.\% relative to the dry film) dispersed within the silicone matrix [6-11]. In this manner they could design coatings with chemically evolving surfaces during water immersion [12]. The most efficient amphiphilic copolymers contain PEGylated-perfluoroalkyl pending groups which can migrate to the extreme surface of the PDMS elastomer, and provide an ambiguous and unpredictable surface towards fouling species [13-15]. Zwitterionic polymers were also used in PDMS-based FRC. Jiang et al. [16] reported a wide range of polyelectrolytes, some of them are tunable surface-tethered zwitterionic polymers which can switch between a polycationic form (antimicrobial effect) and a zwitterionic form (non-fouling effect) through a hydrolysis mechanism. Many reviews explained all the benefits and efficiency of new generation of FRCs with for examples, nanocomposites-based non-stick coatings, textured and chemically functionalized surfaces or biomimetic surfaces $[\mathbf{3 , 1 7 - 2 1 ]}$.

In this work, the strategy is to combine both the antiadhesive properties of silicone elastomers (due to their low surface free energy, low elastic modulus) with a hydrolyzable polyester which would enable the erosion of the coating. Indeed, polyesters are well known to display hydrolytic degradation properties [22]. Thus, they are good candidates to provide erosion properties to PDMS elastomers when inserted in the network as macro-crosslinkers. To design this ambivalent network, polyesters such as poly(D,L-lactide-co-glycolide) (PLGA), poly( $\varepsilon$ caprolactone) (PCL) and PCL- $b$-PDMS- $b$-PCL were chosen according to their different kinetics of hydrolysis and degrees of crystallinity (Fig. 1)[23,24]. PLGA with a LA/GA molar ratio of 75/25 was synthesized as this polyester is known to hydrolyze faster than PCL in a phosphate-buffered solution at $\mathrm{pH}=7.4$ at $37^{\circ} \mathrm{C}$, as described by Pitt et al.[23]. Indeed, PLGA 70/30 weight loss was 91 wt $\%$ in 83 days against 13 wt $\%$ for PCL. Besides the triblock PCL- $b$-PDMS- $b$-PCL copolymer was selected to study the influence of the central PDMS block on the PCL dispersion within the elastomeric silicone and on the degradation kinetics. Azemar et al. [24] found that the presence of a PDMS central block could accelerate the hydrolysis of the polyester block in copolymers. The three polyesters, mentioned above, were modified at their chain ends with alkoxysilane functions to react with bis-silanol PDMS as polyester macrocrosslinkers. The resulting crosslinked (polyester-PDMS) elastomers are expected to act like an erodible coating thanks to a progressive erosion in water which can be whether surface erosion or bulk erosion. The content of polyester segments within the dry coating varied from 12 to $20 \mathrm{wt} \%$.

(a)

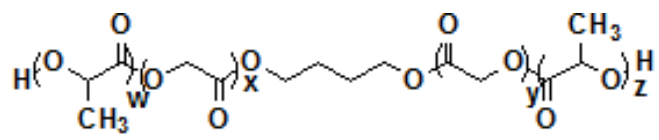

(b)

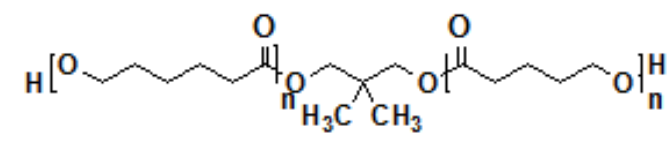

(c)

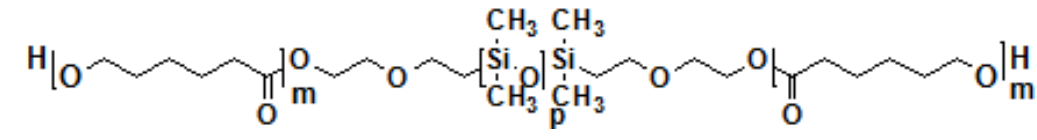

Fig. 1. Chemical structure of a) poly(D,L-lactide-co-glycolide) b) PCL c) PCL-b-PDMS- $b$-PCL. 
The efficacy of the crosslinking reaction of these PDMS-polyester networks was investigated by a residue extraction in solvent. The FRCspecific properties of the coatings (surface free energy, water contact angles and roughness) were evaluated before and after immersion in deionized water. The effect of the polyester segments on the elastic modulus of PDMS/polyester elastomer networks was investigated. The degradation properties of the resulting coatings were studied by mass loss measurements during immersion in deionized water to assess their potential erosion. The study was performed on coatings without any fillers or pigments to evaluate only the influence of the polymer network.

\section{Experimental}

\subsection{Materials}

D,L-lactide (LA), glycolide (GA), 1,4-butanediol (BD), stannous 2-ethylhexanoate and (3-isocyanatopropyl)trimethoxysilane (IPTMS) were purchased from Alfa Aesar. Poly(ع-caprolactone)-diol (MW 2000) with neopentyl glycol as an initiator (NEO) was supplied by Perstrop and used without further purification. A polyester modified polysiloxane triblock copolymer (with $\mathrm{M}_{\mathrm{n}(\mathrm{NMR})}=6800 \mathrm{~g} / \mathrm{mol} ; \mathrm{M}_{\mathrm{n}(\mathrm{NMR})}$ (PDMS block) $\approx 2200 \mathrm{~g} / \mathrm{mol}$; the total PCL end blocks $\approx 4600 \mathrm{~g} / \mathrm{mol})$ and a polydiethoxysiloxane (PDES) crosslinking agent $\left(\mathrm{M}_{\mathrm{n}(\mathrm{NMR})}=744 \mathrm{~g} / \mathrm{mol}\right) \mathrm{were}$ kindly supplied by Evonik. Dioctyltin dilaurate (DOTDL) catalyst was kindly supplied by TIB Chemicals. Bis-silanol polydimethylsiloxane oil (HO-PDMS-OH) (MW 24 000) was kindly supplied by Dow Corning. Tetrahydrofuran (THF) was purchased from Carlo ERBA and used as received. Anhydrous chloroform was provided by Sigma-Aldrich. Deuterated chloroform $\left(\mathrm{CDCl}_{3}\right)$ and THF- $\mathrm{d}_{8}$ were purchased from Eurisotop.

\subsection{Synthesis of poly(D,L-lactide-co-glycolide) (PLGA)}

Poly(D,L-lactide-co-glycolide) (PLGA) was prepared by a ring-opening polymerization using 1,4-butanediol as an initiator. 1,4-butanediol $(1.75 \mathrm{~g}, 19.4 \mathrm{mmol})$, D,L-lactide monomer $(10.50 \mathrm{~g}, 72.9 \mathrm{mmol})$ and glycolide monomer $(2.82 \mathrm{~g}, 24.3 \mathrm{mmol})$ were charged into a dry roundbottomed flask equipped with a stopcock [25-29]. The chosen monomers/initiator molar ratio of 5 is expected to give us a molar mass target of $1000-1500 \mathrm{~g} / \mathrm{mol}[\mathbf{2 7 , 3 0 , 3 1 ]}$. Argon was bubbled into the solution for $20 \mathrm{~min}$. A solution of anhydrous chloroform (15 mL) containing the stannous 2-ethylhexanoate catalyst [monomers/catalyst ratio $(\mathrm{M} / \mathrm{C})=1000$ ] was previously prepared in a nitrogen flushed flask and injected with a dried syringe into the round-bottomed flask. The resulting solution was degassed by three consecutive freeze-pump-thaw cycles. The reaction was then carried out in a preheated oil bath at $150^{\circ} \mathrm{C}$ under an argon atmosphere for $22 \mathrm{~h}$ with stirring. The product was then dissolved in a small amount of chloroform and then precipitated in cold pentane. The precipitate was dried under vacuum overnight. ${ }^{1} \mathrm{H}$

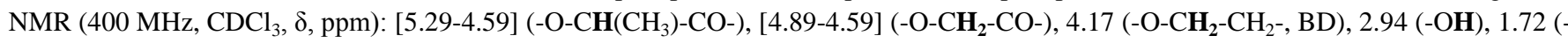
$\mathrm{O}-\mathrm{CH}_{2}-\mathrm{CH}_{2}$, $\left.\mathrm{BD}\right), 1.57$ (-O-CH(CH$\left.)_{3}-\mathrm{CO}-\right)$.

${ }^{1} \mathrm{H}$ NMR was used to calculate the conversion rates of LA and GA monomers, the internal reference was the signal at 4.17 ppm attributed to the BD initiator $\left(-\mathrm{CH}_{2}-\right)$ and was fixed at $4 \mathrm{H}$.

\subsection{Synthesis of polyester macrocrosslinkers}

Polyesters were silanized at their chain ends with the IPTMS crosslinking agent (Fig. 2) [32]. The three hydroxyl-terminated polyesters were first dissolved in anhydrous chloroform with the dioctyltin dilaurate catalyst in a round-bottomed flask equipped with a stopcock. After argon bubbling, the solution was degassed by two consecutive freeze-pump-thaw cycles. The crosslinking agent was then injected with a dried syringe into the round-bottomed flask through a rubber stopper and the solution was again degassed by two consecutive freeze-pump-thaw cycles. All these precautions were important to prevent methoxysilane functions from early hydrolysis. The solution was stirred under an argon atmosphere for 3hours at 35. However, in the case of PCL- $b$-PDMS- $b$-PCL, the silanization required a longer reaction time (5 hours) as well as a higher temperature $\left(65^{\circ} \mathrm{C}\right)$ because of a slower reaction kinetic probably due to the higher molar mass of the copolymer (or due to the presence of a PDMS block). The resulting product was precipitated in cold pentane. In the case of PCL- $b$-PDMS- $b$-PCL, the precipitation solvent was the heptane. The precipitate was dried under vacuum overnight.

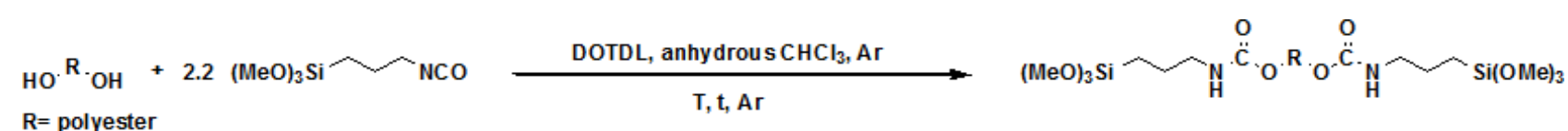

Fig. 2. General synthetic pathway of silanization reaction of the polyester-based polymers. 
${ }^{1} \mathrm{H}$ NMR $\left(400 \mathrm{MHz}, \mathrm{CDCl}_{3}, \delta\right.$, ppm) for silanized PCL- $b$-PDMS- $b$-PCL: 4.84 (wide singlet, -NH-COO-CH $\left.2^{-}\right), 4.05\left(73 \mathrm{H}, \mathrm{t},-\mathrm{CH}_{2}-\mathrm{O}-\right)$ ),3.56 $\left(18 \mathrm{H},-\mathrm{Si}\left(\mathrm{OCH}_{3}\right)_{3}\right), 3.15\left(4 \mathrm{H}, \mathrm{t},-\mathrm{CH}_{2}-\mathrm{NHCOOR}-\right), 2.30\left(73 \mathrm{H}, \mathrm{t}-\mathrm{CH}_{2} \mathrm{CO}-\right), 1.63\left(158 \mathrm{H}, \mathrm{m},-\mathrm{CH}_{2}-\mathrm{PCL}\right), 1.37$ (73H, m, -CH $\left.2^{-} \mathrm{PCL}\right), 0.63$ $\left(4 \mathrm{H}, \mathrm{t},-\mathrm{Si}-\mathrm{CH}_{2}-\left(\mathrm{CH}_{2}\right)_{2}-\mathrm{NH}-\right), 0.52\left(4 \mathrm{H}, \mathrm{t}, \mathrm{Si}\left(\mathrm{CH}_{3}\right)_{2}-\mathrm{CH}_{2}-\right), 0.06\left(170 \mathrm{H}, \mathrm{Si}\left(\mathrm{CH}_{3}\right)_{2}\right)$.

${ }^{1} \mathrm{H}$ NMR (400 MHz, $\left.\mathrm{CDCl}_{3}, \delta, \mathrm{ppm}\right)$ for silanized PCL: 4.84 (wide singlet, -NH-COO-CH $\left.2^{-}\right), 4.05\left(34 \mathrm{H}, \mathrm{t},-\mathrm{CH}_{2}-\mathrm{O}-\right)$ ), 3.85 (4H, s, - $\mathrm{CH}_{2^{-}}$, $\mathrm{NEO}), 3.56\left(18 \mathrm{H}, \mathrm{s},-\mathrm{Si}\left(\mathrm{OCH}_{3}\right)_{3}\right), 3.15\left(4 \mathrm{H},-\mathrm{CH}_{2^{-}} \mathrm{NHCOOR}-\right), 2.26\left(34 \mathrm{H}, \mathrm{t},-\mathrm{CH}_{2}-\mathrm{CO}-\right), 1.60\left(72 \mathrm{H}, \mathrm{m},-\mathrm{CH}_{2^{-}}\right), 1.36\left(34 \mathrm{H}, \mathrm{m},-\mathrm{CH}_{2^{-}}\right), 0.94$ $\left(6 \mathrm{H}, \mathrm{s},-\mathrm{CH}_{3}, \mathrm{NEO}\right), 0.63\left(4 \mathrm{H}, \mathrm{t},-\mathrm{Si}-\mathrm{CH}_{2}-\left(\mathrm{CH}_{2}\right)_{2}-\mathrm{NH}-\right)$.

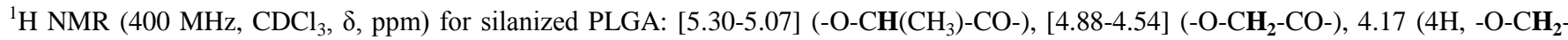
$\left.\mathrm{CH}_{2^{-}}, \mathrm{BD}\right), 3.56\left(18 \mathrm{H}, \mathrm{s},-\mathrm{Si}\left(\mathrm{OCH}_{3}\right)_{3}\right), 3.15\left(4 \mathrm{H},-\mathrm{CH}_{2}-\mathrm{NHCOOR}-\right), 1.72$ (4H, -O- $\left.\mathrm{CH}_{2}-\mathrm{CH}_{2^{-}}, \mathrm{BD}\right), 1.57$ (-O-CH(CH $\left.)^{-\mathrm{CO}-}\right), 0.63(4 \mathrm{H},-\mathrm{Si}-$ $\left.\mathrm{CH}_{2}-\left(\mathrm{CH}_{2}\right)_{2}-\mathrm{NH}-\right)$.

$1 \mathrm{H}$ NMR was used to calculate the conversion rates of the three silanized polymers. For the silanized PCL-b-PDMS-b-PCL, the internal reference was the signal at $0.52 \mathrm{ppm}$ attributed to the - $\mathrm{CH} 2$ - contained in the PDMS block ( $\mathrm{t},-\mathrm{Si}(\mathrm{CH} 3) 2-\mathrm{CH} 2-)$ and was fixed at $4 \mathrm{H}$. For the silanized PCL, the internal reference was the signal at $3.85 \mathrm{ppm}$ attributed to the NEO initiator (s, -CH2-, NEO) and was fixed at 4H. For the silanized PLGA, the internal reference was the signal at $4.17 \mathrm{ppm}$ attributed to the BD initiator (-O-CH2-CH2-, BD) and was fixed at 4H.

\subsection{Preparation of coatings}

The reference coating, pristine PDMS elastomer, was prepared by adding a solution of PDES in THF to the bis silanol-terminated PDMS with a SiOH:SiOEt molar ratio of 100:3.3, considering a PDES functionality of 12. PDMS/polyester networks were prepared using the polyester macrocrosslinkers with the same molar ratio of reactive functions [ $\mathrm{SiOH}: \mathrm{SiOMe}=100: 3.3]$, with a macrocrosslinker functionality
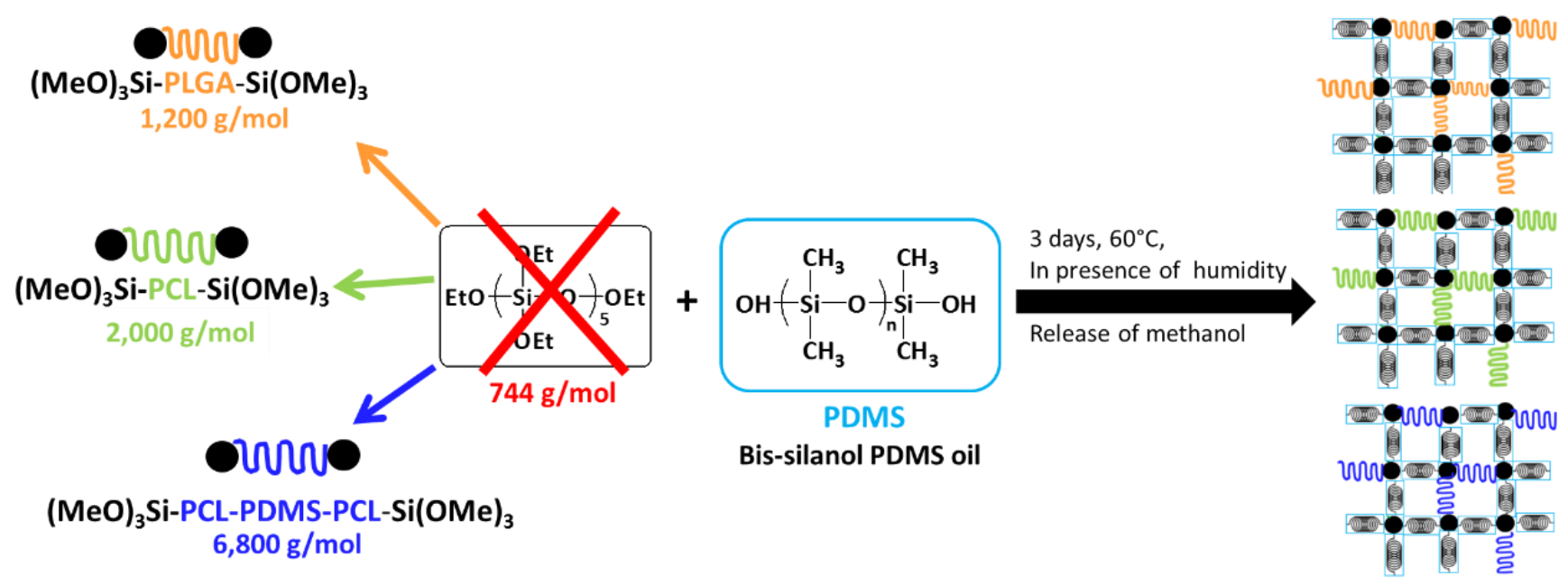

PDMS/polyester networks

Fig.3. General pathway of polyester/PDMS coatings via a condensation cure between polyester-based macrocrosslinkers and a bis-silanol PDMS oil.

of 6 (Fig. 3).

The macrocrosslinkers were dissolved in THF and consecutively dispersed within the bis silanol-terminated PDMS for 20 min. The DOTDL catalyst $(\approx 0.3 \mathrm{wt} . \%$ in the total solution) and the co-solvent $(\mathrm{EtOH})$ were further added into the solutions (Table 1). The coatings were formed by casting 1.5 to $2 \mathrm{~g}$ of the [20-55] \% (wt/wt) THF-based formulations onto cleaned glass microscope slides $\left(76 \times 24 \mathrm{~mm}^{2}\right)$. Homogeneous thick film coatings were dried for 3 days at $60^{\circ} \mathrm{C}$ in a humidity saturated atmosphere with a daily renewal of the air to remove the released methanol and co-solvent. The dry coating thickness was 480-660 $\mu \mathrm{m}$, measured by a micrometer gauge. As regards the nomenclature of the coatings: $\mathrm{N}$ stands for network, $\mathrm{X} / \mathrm{Y}$ corresponds to the mass fraction of the polyester segments (X) on PDMS chains (Y) in the dry coating.

Table 1

Coating formulation recipe.

\begin{tabular}{|c|c|c|c|c|}
\hline Coating ID & Polyester & PDMS (wt.\%) & $\begin{array}{c}\text { Macrocrosslinker } \\
(\text { wt.\%) }\end{array}$ & Solvent/co-solvent (wt.\%) \\
\hline
\end{tabular}




\begin{tabular}{lcccc}
\hline PDMS & None & 74.8 & 2.5 (PDES) & $22.4 / 0$ \\
PLGA-N88/12 & P(D,L-LA-co-GA) & 56.0 & 7.3 & $33.6 / 2.8$ \\
PCL-N83/17 & PCL & 53.6 & 11.3 & $32.2 / 2.7$ \\
TGO-N73/27 & PCL-PDMS-PCL & 26.8 & 18.2 & $53.6 / 1.3$ \\
\hline
\end{tabular}




\subsection{Proton Nuclear Magnetic Resonance Spectroscopy}

${ }^{1} \mathrm{H}$ NMR spectra was recorded on a Bruker Advance III HD 400 spectrometer with a frequency of $400 \mathrm{MHz}$ and using $\mathrm{CDCl}_{3}$ as the solvent.

\subsection{Size Exclusion Chromatography (SEC)}

The number average molar mass $\left(\mathrm{M}_{\mathrm{n}}\right)$ and the dispersity $(\mathrm{D})$ were determined by size exclusion chromatography. Size exclusion chromatography was performed using a Waters 1515 HPLC pump equipped with Styragel HR1, HR4, HR5 columns and a Waters 2414 refractive index detector. The measurements were performed using toluene as eluent at a flow rate of $1.0 \mathrm{~mL} / \mathrm{min}$ at $30^{\circ} \mathrm{C}$. Polystyrene standards $\left(M_{n}\right.$ values varied from 400 to $\left.20,000 \mathrm{~g} / \mathrm{mol}\right)$ were used to generate the calibration curve. Data were analyzed using Breeze software (Waters).

\subsection{Differential Scanning Calorimetry (DSC)}

The thermal behavior of polyesters and PDMS/polyester networks was analyzed on a TA instrument system under a nitrogen flow of $50 \mathrm{~mL} / \mathrm{min}$. To determine the glass transition temperature $\left(\mathrm{T}_{\mathrm{g}}\right)$ of amorphous PLGA, the sample $(10 \mathrm{mg})$ was first heated at $100^{\circ} \mathrm{C}$ for $2 \mathrm{~min}$ then cooled down to $-90^{\circ} \mathrm{C}$ at a rate of $5^{\circ} \mathrm{C} / \mathrm{min}$, kept at $-90^{\circ} \mathrm{C}$ for $2 \mathrm{~min}$, and then reheated to $100^{\circ} \mathrm{C}$ at a rate of $10^{\circ} \mathrm{C} / \mathrm{min}$. To determine the glass transition temperature of semi-crystalline PCL, modulated DSC was performed, the sample was first heated at $100^{\circ} \mathrm{C}$ for 2 min then cooled down to $-90^{\circ} \mathrm{C}$ at a rate of $5^{\circ} \mathrm{C} / \mathrm{min}$, kept at $-90^{\circ} \mathrm{C}$ for $2 \mathrm{~min}$, and then reheated to $100^{\circ} \mathrm{C}$ at a rate of $2^{\circ} \mathrm{C} / \mathrm{min}$. To determine the crystallinity $\left(\mathrm{X}_{\mathrm{c}} \%\right.$ ) of PCL, PCL-PDMS-PCL, and PDMS/polyester network, samples (10-15 mg) were first heated at $100^{\circ} \mathrm{C}$ for $2 \mathrm{~min}$ then cooled down to $-90^{\circ} \mathrm{C}$ at a rate of $1^{\circ} \mathrm{C} / \mathrm{min}$, kept at $-90^{\circ} \mathrm{C}$ for $2 \mathrm{~min}$, and then reheated to $100^{\circ} \mathrm{C}$ at a rate of $1{ }^{\circ} \mathrm{C} / \mathrm{min}$. All DSC values were obtained from the second heating.

\subsection{Residue extraction test}

Several pieces of the same elastomer coating $(\approx 50 \mathrm{mg})$ were introduced into a $1 \mathrm{~mL}$ volumetric flask and filled with THF- $\mathrm{d}_{8}$ and an internal reference (heptane) which was required to calculate the residue content. The elastomeric materials were allowed to swell for 12 hours. Then, THF- $\mathrm{d}_{8}$ was withdrawn and analyzed by ${ }^{1} \mathrm{H}$ NMR to quantify the residue content.

\subsection{Roughness measurement}

Surface roughness profiles were measured by a contact type stylus profiler (Taylor Hobson) using a $2 \mu \mathrm{m}$ radius tip and a $0.1 \mu \mathrm{m}$ radius diamond tip with a minimum applicable $1 \mathrm{mN}$ stylus load. The stylus moved across $15 \mathrm{~mm}$ length of the coating surface at a constant velocity of $0.50 \mathrm{~mm} / \mathrm{s}$ to obtain surface height variation. $\mathrm{R}_{\mathrm{a}}$ values were assessed from the average of three measurements. According to ISO 4288-1996, the selected cut-off was $\lambda c=0.8 \mathrm{~mm}$ except for TGO-N73/27 where $\lambda \mathrm{c}=2.5 \mathrm{~mm}$ since $\mathrm{R}_{\mathrm{a}}>2 \mu \mathrm{m}$. A $\lambda \mathrm{s}$ value of $0.0025 \mathrm{~mm}$ was taken for all samples. For the immersion time of 5 weeks, the coatings were previously removed from deionized water and dried during 6 hours at room temperature before the roughness analysis.

\subsection{Dynamic mechanical analysis (DMA)}

The storage modulus E' (MPa) of the samples was determined at $25^{\circ} \mathrm{C}$ with a dynamic mechanical analyzer DMA (TA Instrument Q800) operating in tensile strain-sweep mode. A frequency of $1 \mathrm{~Hz}$, a preload of $0.01 \mathrm{~N}$, and amplitudes from 5 to $50 \mu \mathrm{m}$ (within the linear viscoelastic region) were used. The results are the average of at least 5 measurements on 3 different samples. The dynamic mechanical analyses were performed using free standing films of [10-14] mm length, [8-10] mm width and [0.6-1.0] mm thick. 


\subsection{Surface free energy measurements}

Static contact angle measurements were performed using a DSA 30 apparatus (Krüss, Germany) by the sessile drop technique. Five contact angle measurements $(\theta)$ were carried out with $2 \mu \mathrm{L}$-droplets of deionized water and $n$-hexadecane, after 4 seconds of stabilization. The surface free energies of the coatings were determined by the Krüss Advance software using the Owens Wendt method. Both the dispersive and polar components were assessed $\left(\gamma_{\boldsymbol{S}}=\gamma_{\mathbf{S}}^{\mathbf{D}}+\gamma_{\mathbf{S}}^{\mathbf{P}}\right)$. Measurements were performed on pristine samples and samples immersed in deionized water for 5 weeks.

\subsection{Dynamic contact angle (DCA)}

DCA experiments were carried out by the advancing-receding drop method using the DSA 30 apparatus under ambient conditions. A deionized water drop is grown on a syringe tip and is picked up by the surface with a withdrawal rate of $0.75 \mu \mathrm{L} / \mathrm{s}$ and the final droplet volume is $25 \mu \mathrm{L}$. The syringe tip never leaves the liquid drop. For each coating, the reported advancing $\left(\theta_{\mathrm{w}, \text { adv }}\right)$ and receding $\left(\theta_{\mathrm{w}, \mathrm{rec}}\right)$ contact angles were the average values obtained from 1 cycle of advancing-receding on 3 deionized water droplets. DCA experiments were carried out on both polyester films and PDMS/polyester coatings. Polyester films were prepared by dissolving the polymer in THF (50 wt.\%) and casting the solution on a glass slide. The glass slides were suspended to get rid of the solvent and thus provide a very thin layer of polymer.

\subsection{Hydrolytic degradation test}

A mass loss study was carried out on the coated glass slides immersed for 5 weeks in deionized water. Before gravimetric measurements, the coatings were gently rinsed with deionized water and dried at room temperature for 6 hours. The reported mass loss results are the mean value of three replicates. The mass loss (wt.\%) was calculated using Eq. 1:

$$
\text { Mass loss } \%=\frac{(\text { Wo-Wt })}{(\text { Wo-Ws })} \times 100
$$

Where Wo is the initial mass of the coated glass slide, Wt is the mass of the coated glass slide after an immersion time $t$ and $\mathbf{W s}$ is the mass of the glass slide alone.

\section{Results and discussion}

\subsection{Synthesis of poly(D,L-lactide-co-glycolide) (PLGA)}

It should be mentioned that very few articles describe the synthesis of low molar mass poly(D,L-lactide-co-glycolide) (with $\mathrm{Mn} \leq 5,000 \mathrm{~g} / \mathrm{mol})[\mathbf{3 3}, \mathbf{3 4}]$. The synthesized PLGA exhibited a number average molar mass $\left(\mathrm{M}_{\mathrm{n}, \mathrm{SEC}}\right)$ of $880 \mathrm{~g} / \mathrm{mol}$ with low dispersity (Đ). This low molar mass may facilitate the dispersion of PLGA within the soft silicone oil. Beside this advantage, it is known that low molar mass polyesters degrade faster in water than higher molar mass polymers [35], which is a required condition in our study. The D,L-lactide was preferred to the $\mathrm{D}$ or $\mathrm{L}$ enantiomers as the polymers of the latter ones are semi-crystalline polymers whereas the polymerized racemic form is amorphous due to the irregularities in the polymer main chain [36]. The amorphous state of the p(DL-lactide-co-glycolide) is interesting since amorphous phases can be faster hydrated than crystalline phases, and thus will undergo faster hydrolytic degradation $[\mathbf{2 4 , 3 5}$. For example, the intrinsically amorphous racemic poly(DL-lactic acid) has a mass loss of $90 \%$ after 12 weeks in a buffered solution $\left(\mathrm{pH}=7.4\right.$ and $\mathrm{T}=37^{\circ} \mathrm{C}$ ) whereas the amorphous poly(L-lactic acid) has a mass loss of $50 \%$ after 110 weeks in the same conditions [37,38]. The mixture of LA and GA monomers gives more advantages regarding the hydrolysis kinetics. PLA is more hydrophobic than P(DL-lactideco-glycolide) leading to a lower water absorption into the polymer [35,39]. The 75/25 (LA/GA) molar ratio was chosen for its fast hydrolysis kinetics combined with its good solubility in most organic solvents, contrary to the 50/50 (LA/GA) ratio which exhibits a fastest hydrolysis kinetics, but caused a lower solubility due to the increase of GA units [25,39]. No residual 1,4-butanediol was found at the end of the polymerization (before precipitation).Only lactide monomers were found in small amount ( 2 mol. \%) but were eliminated during the precipitation step in pentane. The conversion of both LA and GA monomers was calculated according to Eqs. 2 and 3, respectively:

$$
\begin{aligned}
& \text { Conversion LA (\%) }=100-\frac{\mathrm{I}_{5.04}^{\mathrm{LA} \text { monomer }} / 2}{\mathrm{I}_{5.04}^{\mathrm{LA} \text { monomer }} / 2+\mathrm{I}_{5.30-5.07}^{\mathrm{LA} \mathrm{polymer}} / 2} \times 100 \quad \text { Eq. } 2 \\
& \text { Conversion GA (\%) }=100-\frac{\mathrm{I}_{4.92}^{\mathrm{GA} \text { monomer }} / 4}{\mathrm{I}_{4.92}^{\mathrm{GA} \text { monomer }} / 4+\mathrm{I}_{4.88-4.54}^{\mathrm{GA} \text { polymer }} / 4} \times 100 \quad \text { Eq. } 3
\end{aligned}
$$


Where $\mathrm{I}_{5.04}^{\mathrm{LA} \text { monomer }}$ corresponds to the intensity of the signal at $5.04 \mathrm{ppm}\left(\mathrm{q},-\mathrm{CH}-\mathrm{of} \mathrm{LA}\right.$ monomer), $\mathrm{I}_{5.30-5.07}^{\mathrm{LA}}$ polymerresponds to the intensity

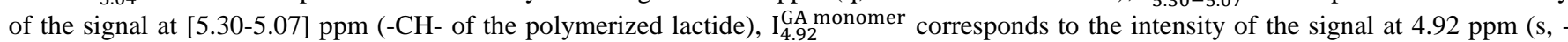
$\mathrm{CH} 2$ - of the GA monomer) and $\mathrm{I}_{4.88-4.54}^{\mathrm{GA} \text { polymer }}$ corresponds to the intensity of the signal [4.88-4.54] ppm (-CH2- of the polymerized glycolide).

The resulting synthesized poly(D,L-lactide-co-glycolide) was a transparent, sticky oil with a (LA/GA) molar ratio of 74/26, LA conversion of $98 \%$, GA conversion of $100 \%$ and a yield of $87 \%$.

\subsection{Physico-chemical and thermal properties of polyesters}

Poly(D,L-lactide-co-glycolide), poly( $\varepsilon$-caprolactone) and PCL- $b$-PDMS- $b$-PCL were characterized by NMR and SEC to assess their number-average molar mass as well as their dispersity. DSC was used to assess their degree of crystallinity and their melting temperature $\left(\mathrm{T}_{\mathrm{m}}\right)$ or glass transition temperatures $\left(\mathrm{T}_{\mathrm{g}}\right)$ when existing (Table 2).

The three polyesters displayed molar masses below $10 \mathrm{~kg} / \mathrm{mol}$. The PCL- $b$-PDMS- $b$-PCL triblock copolymer with block of respective molar masses 2,300- $b-2,200-b-2,300$ had a lower crystallinity $(28 \%)$ than a PCL of $\left.4,000 \mathrm{~g} / \mathrm{mol}_{(\mathrm{C}}=77 \%\right)$ and a PCL of $2,000 \mathrm{~g} / \mathrm{mol}\left(\mathrm{X}_{\mathrm{c}}=60 \%\right)$ [40] thanks to its central PDMS block which brings flexibility to the polymer chain. PCL and PCL- $b-$ PDMS- $b$-PCL are semi-crystalline polymers with $\mathrm{T}_{\mathrm{m}}$ values around $40-50^{\circ} \mathrm{C}$ as expected [40,41] while PLGA is amorphous. At room temperature, this last polyester is a very viscous and transparent oligomer, its very low molar mass (with low dispersity) explains its $\mathrm{T}_{\mathrm{g}}$ at $-23.5^{\circ} \mathrm{C}$ contrary to PLGA $75 / 25$ with molar masses ranging from 10,000 to 70,000 that exhibits $\mathrm{T}_{\mathrm{g}}$ values between $31^{\circ} \mathrm{C}$ and $51^{\circ} \mathrm{C}[\mathbf{3 0 , 4 2 , 4 3 ]}$.

It is worth noting that the $\mathrm{T}_{\mathrm{g}}$ of the PDMS block was not determined due to the inability of the cooling system to reach $-140^{\circ} \mathrm{C}\left(\mathrm{T}_{\mathrm{g}}\right.$ of PDMS is expected to be around $-127^{\circ} \mathrm{C}$ [41]).

Table 2

Physico-chemical and thermal properties of polyesters. ${ }^{\mathrm{a}}$ Crystallinity of PCL, $X c=\frac{\omega(P C L) \times \Delta H_{m} \times 100}{\Delta H_{m}^{\circ}}$ with $\Delta H_{m}^{\circ}=139.3 \frac{\mathrm{J}}{\mathrm{g}}[24]$ and $\omega(\mathrm{PCL})=0.68$ (mass fraction of PCL) for

\begin{tabular}{|c|c|c|c|c|c|c|}
\hline Polymer & $\begin{array}{l}\mathbf{M}_{\mathrm{n}, \mathrm{SEC}} \\
(\mathrm{g} / \mathbf{m o l})\end{array}$ & Đ & $\begin{array}{r}\mathbf{M}_{\mathrm{n}, \mathrm{RMN}} \\
(\mathrm{g} / \mathrm{mol})\end{array}$ & $\mathbf{T}_{\mathbf{g}}\left({ }^{\circ} \mathbf{C}\right)$ & $\mathbf{T}_{\mathrm{m}}\left({ }^{\circ} \mathbf{C}\right)$ & $\begin{array}{cc}\Delta \mathbf{H}_{\mathrm{m}}(\mathrm{J} / \mathrm{g}) & \begin{array}{c}\mathbf{X}_{\mathrm{c}} \\
(\text { polyester })(\%)^{\mathrm{a}}\end{array}\end{array}$ \\
\hline
\end{tabular}

\begin{tabular}{|c|c|c|c|c|c|c|c|}
\hline PLGA & 880 & 1.1 & 1200 & -23.5 & none & 0 & 0 \\
\hline PCL & 1800 & 1.4 & 2000 & -67 & $40-44$ & 70 & 50 \\
\hline PCL- $b$-PDMS- $b$-PCL & 7300 & 1.3 & 6800 & n.d. ${ }^{\mathrm{b}}$ & $52-55$ & 57 & 28 \\
\hline
\end{tabular}

PCL-b-PDMS-b-PCL.

b Not determined for both blocks

\subsection{Synthesis and characterization of polyester macro-crosslinkers}

The silanization reaction of a polyester and IPTMS was investigated by ${ }^{1} \mathrm{H}$ NMR through monitoring the disappearance of peaks attributed to the protons of IPTMS (-C $\mathbf{H}_{2}-\mathrm{NCO}$, triplet at $\left.3.28 \mathrm{ppm}\right),-\mathrm{Si}-\mathrm{CH}_{2^{-}}$triplet at $\left.0.63 \mathrm{ppm}\right)$, of the chain end protons of polyesters $\left(-\mathrm{CH}_{2}-\mathrm{OH}\right.$ at [3.6-3.7] ppm) and the appearance of both the urethane function at $3.15 \mathrm{ppm}$ and $4.84 \mathrm{ppm}\left(-\mathrm{CH}_{2}-\mathrm{NH}-\right.$ COOR and $-\mathrm{CH}_{2}-\mathrm{NH}-\mathrm{COOR}$, respectively) and the protons of $-\mathrm{SiCH}_{2} \mathrm{CH}_{2} \mathrm{CH}_{2} \mathrm{NHCOOR}-$ at 0.63 ppm. The achieved conversions were varying from 90 to $98 \%$ and the yield was comprised between 60 and $80 \%$ depending on the polyester. The conversions were calculated according to Eq. 4 :

$$
\text { Conversion }(\%)=\left(\mathrm{I}_{3.15}^{\mathrm{CH} 2} \text { urethane }\right) / 4 \times 100 \quad \mathbf{E q . 4}
$$

Where $\mathrm{I}_{3.15}^{\mathrm{CH} 2}$ urethane corresponds to the intensity of the signal at $3.15 \mathrm{ppm}\left(\mathrm{t},-\mathrm{CH}_{2}-\mathrm{NHCOOR}-\right)$ due to the formation of the urethane function.

\subsection{Formation of the PDMS/polyester coatings}


Once the PDMS/polyester coatings were dried, a residue extraction test of each sample was carried out to verify the complete crosslinking of the polyester macrocrosslinkers with the bis-silanol PDMS oil. The quantitative analysis of residues was determined by ${ }^{1} \mathrm{H}$ NMR, using Eq. 5 (either for PDMS or polyester macrocrosslinker residues):

$$
\% \text { residue }=\frac{\frac{\frac{[\text { heptane }]}{\mathrm{I}_{0.89} \text { heptane }}}{6} \times \frac{\substack{\text { residue } \\ \mathrm{n}_{\mathrm{H}}}}{\mathrm{m}_{\mathrm{o}}} \times \mathrm{V}_{\mathrm{o}}}{\mathrm{m}_{\mathrm{P}}} \times 100 \text { Eq. } 5
$$

where $n_{H}$ is the number of protons corresponding to the residue signal at $x \mathrm{ppm}$, [heptane] is the concentration of the internal standard heptane in the volumetric flask (in $\mathrm{g} / \mathrm{mL}$ ), $V_{o}$ is the volume of (THF + heptane) within the volumetric flask before the addition of the elastomeric pieces with a mass of $m_{o}$.

The results shown in Table 3 indicate that the polyester macrocrosslinkers reacted well with the bis-silanol PDMS since less than $0.1 \%$ of residue was found in the solvent of extraction.

Table 3

Residue content after extraction in THF- $\mathrm{d}_{8}$.

\begin{tabular}{lcc}
\hline PDMS & $<0.1$ & - \\
PLGA-N88/12 & 0.1 & - \\
PCL-N83/17 & 0.1 & - \\
TGO-N73/27 & & $<0.1$
\end{tabular}

\subsection{Roughness of PDMS/polyester coatings}

The arithmetic average roughness $\left(\mathrm{R}_{\mathrm{a}}\right)$ of the PDMS/polyester coatings was evaluated with a contact type stylus profiler. The mode of application (casting the solution on glass slides) was the same for each coating since the mode of application influences significantly the roughness. The typical roughness $\left(R_{a}\right)$ of a sprayed silicone Fouling Release Coating is usually lower than $2 \mu \mathrm{m}$ [3].

Pristine PDMS coating and PLGA-N88/12 initially showed smooth surfaces $\left(\mathrm{R}_{\mathrm{a}}<0.5 \mu \mathrm{m}\right)$ however PCL-N83/17 and TGON73/27 exhibited higher roughness $(>1-2 \mu \mathrm{m})$ meaning there is a strong effect of the PCL blocks on the surface roughness (Fig. 4). After immersion in deionized water for 5 weeks, an increase of $R_{a}$ was observed for each coating, particularly for the PCL-based coatings $\left(\mathrm{R}_{\mathrm{a}} \geq 2 \mu \mathrm{m}\right)$ which can be explained by the possible surface degradation or polymer chains reorganization. For the PDMS elastomer reference, the roughness slightly increased probably due to the surface migration of a siliceous phase formed by the homocondensation of PDES [44-47].

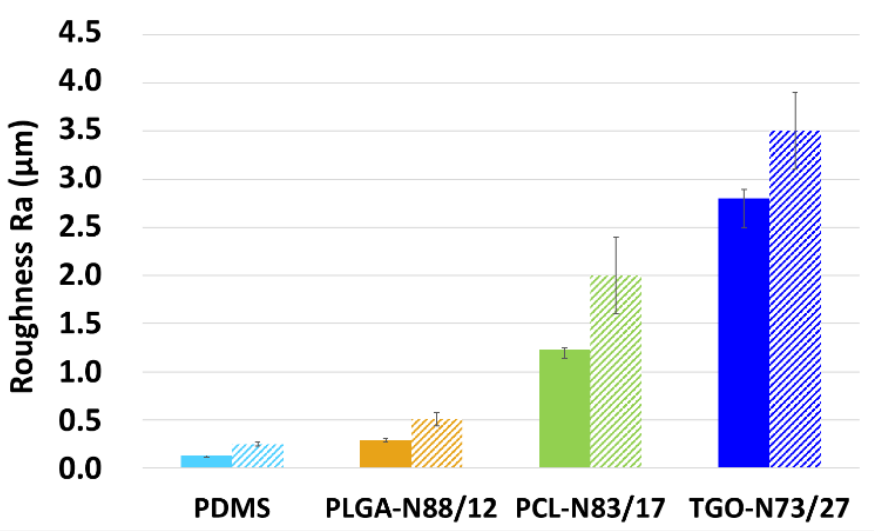

Fig. 4. Arithmetic average roughness $R_{a}$ values of the coating surfaces before (filled pattern) and after 5 weeks of immersion in deionized water 


\subsection{Wetting properties of the PDMS elastomer reference and the polyesters}

The wettability of the PDMS elastomer reference and polyesters was assessed by measuring the advancing $\left(\theta_{\mathrm{w}, \mathrm{adv}}\right)$ and receding $\left(\theta_{\mathrm{w}, \mathrm{rec}}\right)$ contact angles with deionized water droplets. The $\theta_{\mathrm{w}, \mathrm{adv}}$ and $\theta_{\mathrm{w}, \mathrm{rec}}$ values are shown in Table 4 . $\theta_{\mathrm{w}, \mathrm{adv}}$ describes the hydrophobic contribution of the surface since the surface is freshly in contact with water whereas $\theta_{\mathrm{w}, \text { rec }}$ reflects the surface hydrophilic contribution given that the surface has already been wet, especially if a chemical reorganization occurs in contact with water [48].

PLGA and PCL- $b$-PDMS- $b$-PCL films are both hydrophobic surfaces $\left(\theta_{\mathrm{w}, \text { adv }}>100^{\circ}\right)$ similar to the PDMS elastomer reference. PCL showed a more hydrophilic behaviour $\left(\theta_{\mathrm{w}, \mathrm{adv}}=70^{\circ}\right)$. Besides, they all exhibited a contact angle hysteresis $\left(\Delta \theta_{\mathrm{w}}=\theta_{\mathrm{w}, \text { adv }}-\right.$ $\theta_{\mathrm{w}, \mathrm{rec}}$ ) higher than $30^{\circ}$ (even higher than $60^{\circ}$ for PLGA and PCL- $b$-PDMS- $b$-PCL) which suggests that they all exhibit a surface chemical heterogeneity leading to its reorganization in contact with water.

This chemical reconstruction could be potentially interesting to provide an ambiguous surface towards marine species [14].

Table 4

Dynamic water contact angles of polyesters and the PDMS elastomer reference.

\begin{tabular}{lcc}
\hline Polymer & $\boldsymbol{\theta}_{\mathrm{w}, \text { adv }}\left({ }^{\circ}\right)$ & $\boldsymbol{\theta}_{\mathrm{w}, \text { rec }}\left({ }^{\circ}\right)$ \\
\hline PDMS elastomer & $108 \pm 1$ & $98 \pm 2$ \\
PLGA & $102 \pm 2$ & $39 \pm 5$ \\
PCL & $70 \pm 2$ & $38 \pm 2$ \\
PCL- $b$-PDMS- $b$-PCL & $116 \pm 2$ & $47 \pm 3$ \\
\hline
\end{tabular}

\subsection{Surface free energy and wetting properties of the PDMS/polyester coatings}

In this study, the aim was to discuss the effect of the polyester on the coatings surface during immersion in water. Before immersion, for all PDMS/polyester coatings, the dominant contribution of the surface free energy was dispersive, typical of a nonpolar silicone-based surface with $\gamma_{\mathrm{S}} \approx \gamma_{\mathrm{S}}^{\mathrm{D}} \approx[18-26] \mathrm{mJ} / \mathrm{m}^{2}$ (Fig. 5). After 5 weeks of immersion in deionized water, PDMS and PLGA-N88/22 coatings showed surface energies lower or equal to $25 \mathrm{~mJ} / \mathrm{m}^{2}$ whereas PCL-based coatings exhibited higher surface energies between 30 and $40 \mathrm{~mJ} / \mathrm{m}^{2}$. This increase of the surface energy is due to the increase of the polar component only, as the dispersive component still remains the same as before immersion. According to Figure $6, \gamma_{\mathrm{S}}^{\mathrm{P}}$ of TGO-N73/27 increased from $2 \pm 1$ to $17 \pm 2 \mathrm{~mJ} / \mathrm{m}^{2}$ after 5 weeks of immersion and the polar component $\gamma_{\mathrm{S}}^{\mathrm{P}}$ of PCL-N83/17 varied from 0 to $7 \pm 2 \mathrm{~mJ} / \mathrm{m}^{2}$. The higher polar component of TGO-N73/27 after immersion compared with PCL-N83/17 could be explained by the better dispersion of the PDMS block containing copolymer within the bulk coating and thus, it may result in a richer surface in polyester segme nts. The increase of the polar component for PCL-based coatings after immersion suggests that the polar interactions grow owing to the polyester reorganization on the surface. The coatings hydration may have modified the arrangement and distribution of the polyester chains within the PDMS/polyester network.

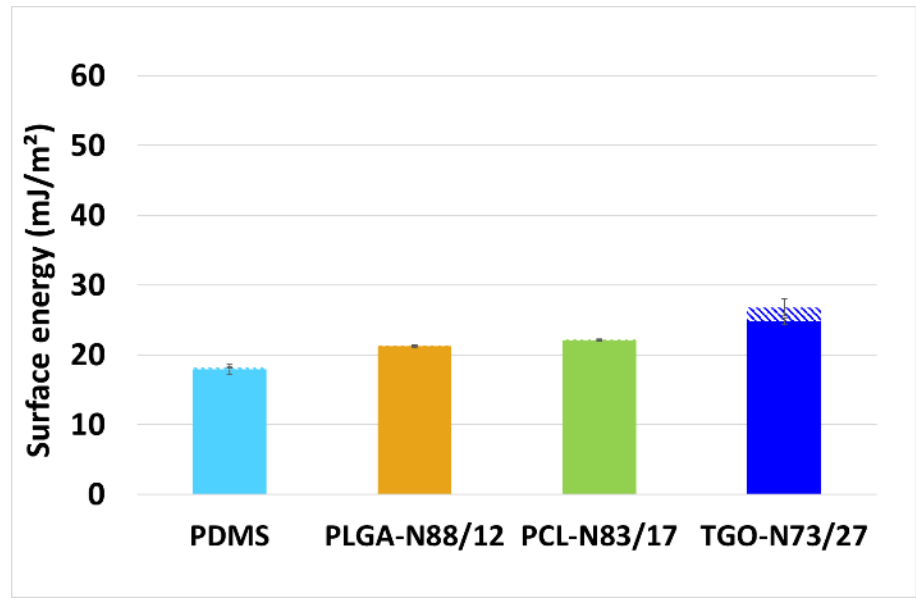

Fig. 5. Dispersive surface free energies ( $\gamma_{S}^{\mathrm{D}}$, filled pattern) and polar surface free energies ( $\gamma_{S}^{\mathrm{P}}$, striped pattern) of pristine coatings.

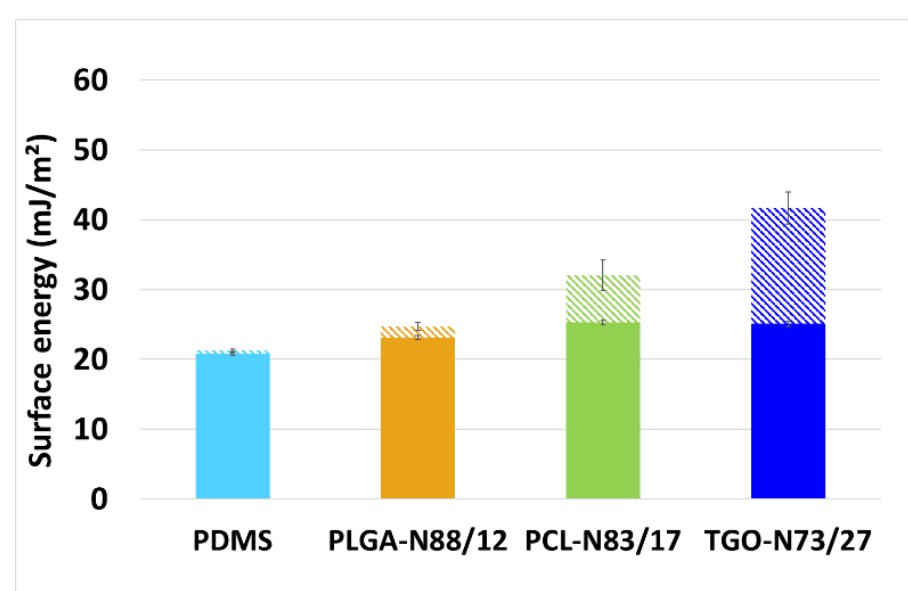

Fig. 6. Dispersive surface free energies ( $\gamma_{S}^{\mathrm{D}}$, filled pattern) and polar surface free energies $\left(\gamma_{S}^{\mathrm{P}}\right.$, striped pattern) of coatings after 5 weeks of immersion in deionized water. 
Regarding the wetting properties, as previously discussed in 3.6., the advancing and receding water contact angles of the coatings can reveal some chemical reorganizations of the surface according to the contact angle hysteresis $\Delta \theta_{\mathrm{w}}\left(\Delta \theta_{\mathrm{w}}=\theta_{\mathrm{w}, \mathrm{adv}}-\theta_{\mathrm{w}, \mathrm{rec}}\right)$. In the literature, this contact angle hysteresis is either explained by a surface roughness, or by a chemical heterogeneity of the surface, or by the ability of functional groups to reorganize on the surface during contact with the liquid [49-52]. In this study, the dynamic contact angles were measured after different immersion times to assess the surface reconstruction of the coatings. Roughness profiler analysis carried out before and after 5 weeks of immersion revealed that the changes in surface roughness were rather significant $\left(R_{a} \geq 2 \mu \mathrm{m}\right.$ in the case of PCL-based coatings), suggesting that the effect of roughness on contact angles is not negligible. The evolution of $\theta_{\mathrm{w}, \text { adv }}$ with immersion time showed a quite similar tendency for the three PDMS/polyester coatings. $\theta_{\mathrm{w}, \text { adv }}$ remained essentially unaffected within the first 2 weeks of immersion for all the PDMS/polyester coatings (between 100 and $120^{\circ}$ ), and then values decreased rapidly below $100^{\circ}$ after 4 weeks (Fig. 7). This trend indicates a gain in surface hydrophilicity which is more pronounced for the TGO-N73/27 coating. $\theta_{\mathrm{w}, \text { rec }}$ values showed more complex profiles during immersion with two distinct behaviors for PLGA-based coatings and PCL-based coatings (Fig. 8). During the first 2 weeks for PLGA-N88/12, $\theta_{\mathrm{w}, \text { rec }}$ was maintained at $65-70^{\circ}$ and then decreased up to $20^{\circ}$. PCL-based coatings exhibited a low value of $\theta_{\mathrm{w}, \text { rec }}$ down to $20^{\circ}$ after only 1 week of immersion, and partially recovered their hydrophobicity [40-60] ${ }^{\circ}$ to finally end up at $20^{\circ}$ after 5 weeks. In both cases, the decrease of $\theta_{\mathrm{w}, \text { rec }}$ is related to a modification in the chemistry and/or morphology of the coating surface in contact with water.

The prediction of wettability of amphiphilic surfaces is complex, because both roughness and surface reorganization could affect this property. For this reason, by neglecting the effect of roughness, we are able to say that all PDMS/polyester coatings become more hydrophilic after water immersion as evidenced by the decreased of both $\theta_{\mathrm{w}, \text { adv }}$ and $\theta_{\mathrm{w}, \text { rec }}$ contrary to the PDMS reference which does not change significantly. This was attributed to a larger exposure of the polyester segments to the outer surface. Thus polyester contents (from 10 to $20 \mathrm{wt} \%$ by respect to the dried coating) seem to be sufficient to provide chemical surface-active coatings.

\subsection{Crystallinity of the PDMS/polyester coatings}

Crystallinity of PDMS/polyester coatings is actually very important to study since it can have a significant impact on their viscoelastic properties as well as on their hydrolytic degradation.

The crystallinity coming from the PDMS is calculated according to

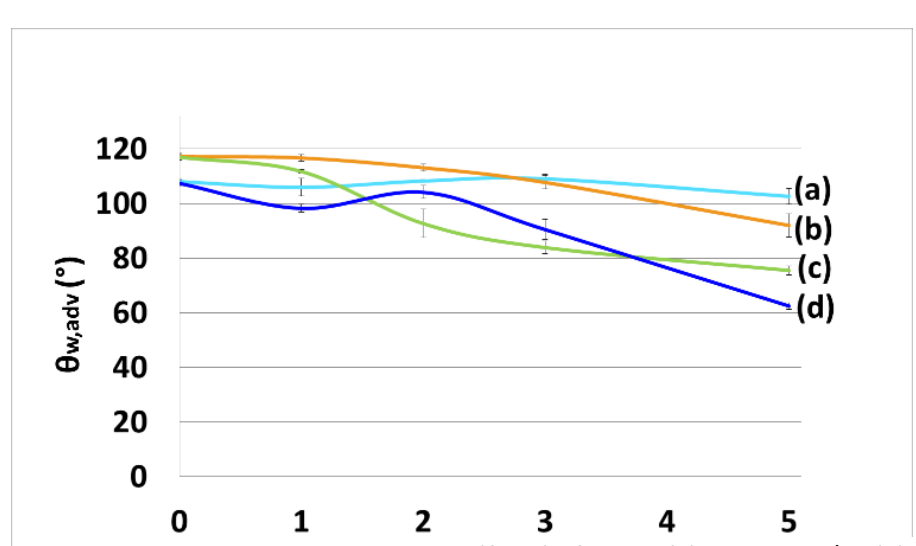

Fig. 7. Water advancing contact angles $\left(\theta_{w, a d v}\right)$ of PDMS (a), PLGA-N88/12 (b), PCL-N83/17 (c) and TGO-N73/27 (d) at different deionized water immersion

times.

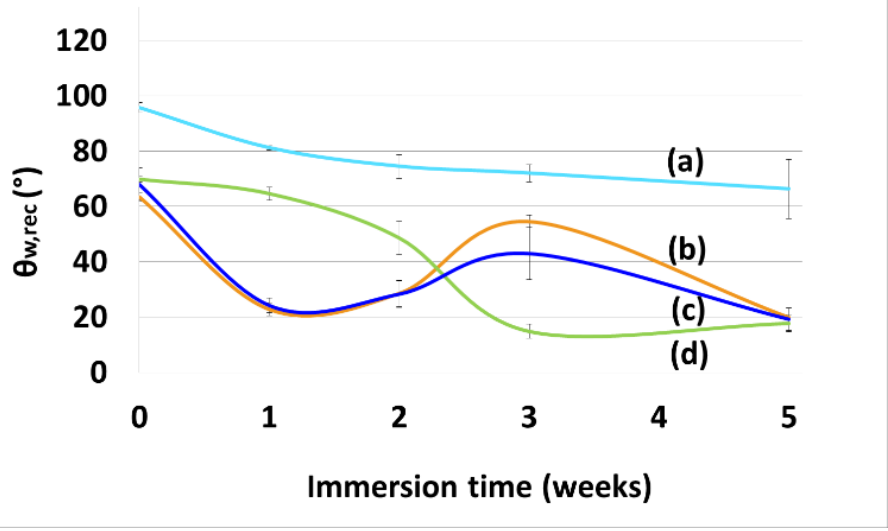

Fig. 8. Water receding contact angles $\left(\theta_{w, r e c}\right)$ of PDMS (a), PLGA-N88/12 (b), TGO-N73/27 (c) and PCL-N83/17 (d) at different deionized water immersion times.

$$
\begin{aligned}
& \mathrm{X}_{\mathrm{c}}(\mathrm{PDMS})=\left(\Delta \mathrm{H}_{\mathrm{m}, \mathrm{sample}}^{\mathrm{PDMS}} \times \mathrm{W}_{\mathrm{PDMS}}\right) \times 100 /\left(\Delta \mathrm{H}_{\mathrm{m}}^{\mathrm{PDMS}, \text { th }}\right) \quad \text { Eq. } 6 \\
& \mathrm{X}_{\mathrm{c}}(\mathrm{PCL})=\left(\Delta \mathrm{H}_{\mathrm{m}, \mathrm{sample}}^{\mathrm{PCL}} \times \mathrm{W}_{\mathrm{PCL}}\right) \times 100 /\left(\Delta \mathrm{H}_{\mathrm{m}}^{\mathrm{PCL}, \text { th }}\right) \quad \text { Eq. } 7
\end{aligned}
$$

Where $\mathrm{Xc}(\mathrm{PDMS})$ is the crystallinity of the cured PDMS, $\mathrm{Xc}(\mathrm{PCL})$, the crystallinity of PCL, $\Delta \mathrm{H}_{\mathrm{m}}^{\text {PDMS }}$ is the measured enthalpy of

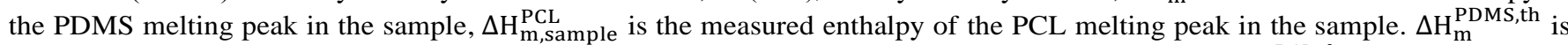
the theoretical melting enthalpy of an unfilled cured PDMS rubber taken equal to $28.35 \mathrm{~J} / \mathrm{g}$ [53]. $\Delta \mathrm{H}_{\mathrm{m}}^{\mathrm{PCL} \text {,th }}$ is the equilibrium melting enthalpy of $100 \%$ crystalline PCL taken equal to $139.3 \mathrm{~J} / \mathrm{g}$ [24]. $\mathrm{W}_{\mathrm{PDMS}}$ and $\mathrm{w}_{\mathrm{PCL}}$ represent the mass fractions of PDMS and PCL respectively in the sample for instance for PLGA-N88/12 sample, $\mathrm{w}_{\mathrm{PDMS}}=0.88$ and $\mathrm{w}_{\mathrm{PCL}}=0.12$.

As shown in Table 5, the PDMS reference exhibited a melting point suggesting that PDMS segments could crystallize within the network [53]. 

The incorporation of polyester segments in the network has an influence on the crystallinity of crosslinked PDMS. The insertion of PLGA affected significantly the crystallinity of the PDMS segment in the PLGA-N88/12 coating. This result could be explained by the amorphous state of PLGA that could make impossible for PDMS chains to order themselves by promoting the flexibility of the network. PCL in the PCL-N83/17 crosslinked network did not disrupt the PDMS organization. Besides, the absence of PCL melting peak on DSC curve (Fig. 9) confirmed that PCL cannot crystallize within the PDMS/polyester network whereas the pure PCL has $50 \%$ of crystallinity.

PCL segments within the PCL- $b$-PDMS- $b$-PCL crosslinker was shown to decrease the crystallinity of PDMS potentially due to the presence of small PCL crystalline phases as evidenced by the presence of a melting enthalpy at $35^{\circ} \mathrm{C}$ shown in Fig. 9 . Here the influence of PDMS block within the PCL-based copolymer can be highlighted. The PDMS block may help PCL segments to crystallize by bringing more chains mobility.

\section{Table 5}

Thermal properties of PDMS and polyester segments in PDMS/polyester networks.

\begin{tabular}{|c|c|c|c|c|c|c|}
\hline Coating ID & $\Delta \underset{(\mathbf{J} / \mathbf{g})}{\Delta H_{\mathrm{m}, \mathrm{sample}}^{\mathrm{PDMS}}}$ & $\mathbf{T}_{\mathbf{m}}$ (PDMS) $\left({ }^{\circ} \mathbf{C}\right)$ & $\mathbf{X}_{\mathrm{c} \text { (PDMS) }}(\%)$ & $\Delta \mathrm{H}_{\mathrm{m}, \mathrm{sample}}^{\mathrm{PCL}}(\mathbf{J} / \mathbf{g})$ & 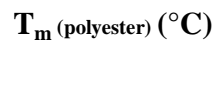 & $\begin{array}{c}\mathbf{X}_{\mathrm{c}} \text { (polyester) } \\
(\%)\end{array}$ \\
\hline PDMS elastomer & 20 & -44 & 70.5 & - & - & 0 \\
\hline PLGA-N88/12 & 7 & -41 & 21.7 & - & - & 0 \\
\hline PCL-N83/17 & 23 & -40 & 67.3 & - & - & 0 \\
\hline TGO-N73/27 & 16 & -40 & 41.2 & 10 & 35 & 2.0 \\
\hline
\end{tabular}

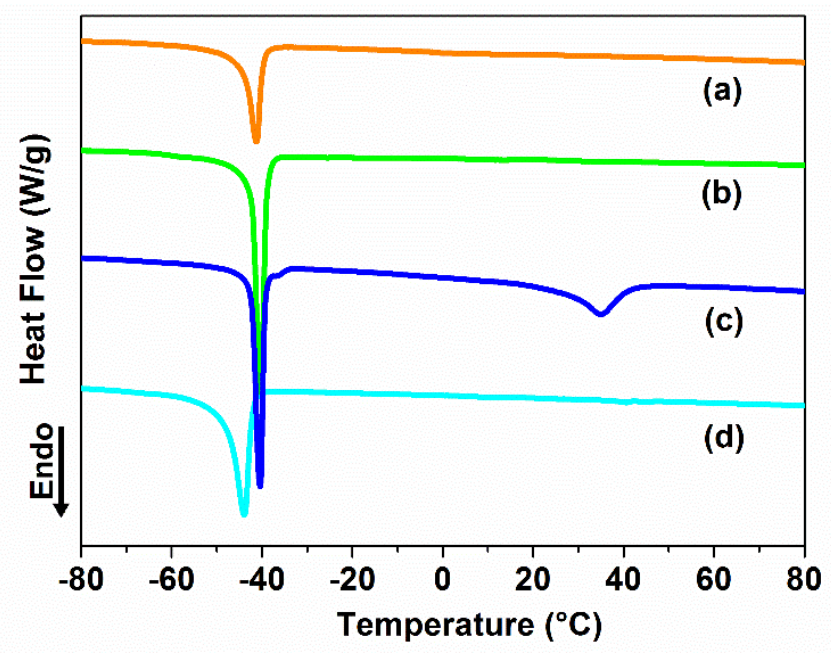

Fig. 9. DSC thermograms of PLGA-N88/12 (a), PCL-N83/17 (b), TGO$\mathrm{N} 73 / 27 / 20$ (c) and PDMS (d) obtained at a heating rate of $1^{\circ} \mathrm{C} / \mathrm{min}$.

\subsection{Viscoelastic properties of the elastomeric films}

The elastic modulus of elastomeric materials depends on multiple parameters such as the amount and functionality of the

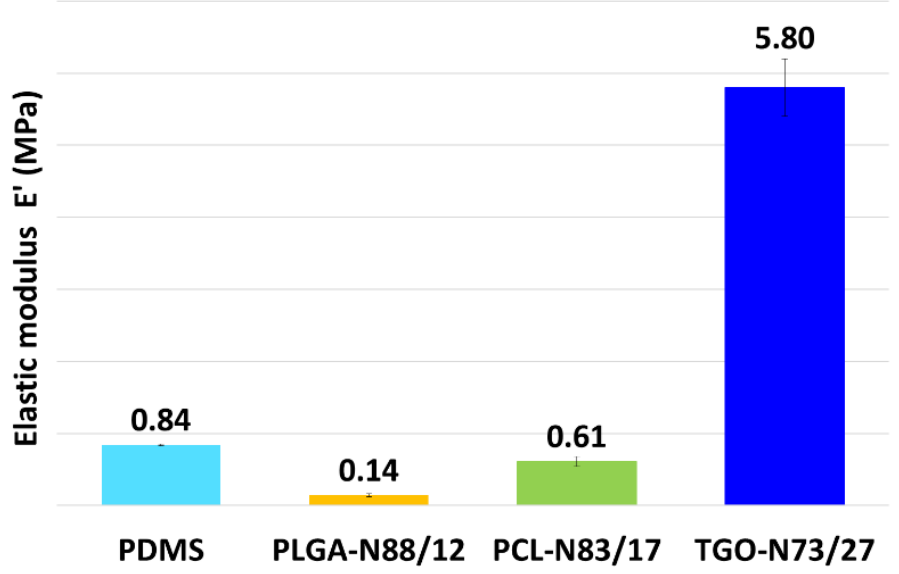


crosslinking agent which governs the crosslinking density, the inter-nodes distance which brings more or less flexibility to the network and thus chains mobility and the nature of crosslinked segments (semi-crystalline, amorphous). In our case, all the films were formulated with the same silanol/alkoxysilane reactive functions molar ratio. Fouling Release Coatings usually exhibit elastic modulus ranging between 0.2 and $9 \mathrm{MPa}$ [3]. The formulated coatings also called "varnishes" do not contain any pigments or fillers contrary to commercially available FRCs. The addition of fillers in the formulations would cause a further increase of the elastic modulus. The four varnishes presented in Fig. 10 had storage modulus below 1 MPa except for TGO-N73/27 which showed a significant increase in rigidity. This significant increase may be attributed to both the higher PCL crystallinity of the network and the high content of PCL- $b$-PDMS- $b$-PCL (40 wt \% in the dry coating). Indeed $40 \mathrm{wt} \%$ of the high molar mass bis-silanol PDMS were substituted by PCL- $b$-PDMS- $b$-PCL $(6,800 \mathrm{~g} / \mathrm{mol})$ which decreased the inter-nodes distance. PLGA-N88/12 and PCL$\mathrm{N} 83 / 17$, on the contrary, exhibited an even lower storage modulus than PDMS with E' lower than 0.8 MPa due to the higher flexibility of the network as previously mentioned.

\subsection{Hydrolytic degradation of the coatings}

The hydrolysis mechanism of polyesters usually takes place following 3 steps "diffusion-reaction-dissolution"[22,25,54,55]. The first step is the adsorption and water diffusion within the bulk polymer (preferably in the amorphous regions) following by the Fig. 10. Elastic modulus ( $\left.E^{\prime}\right)$ at $25^{\circ} \mathrm{C}$ for the different free films.

cleavage of the ester function generating degradation products such as small acidic oligomers (caproïc acid, monomeric lactate and glycolate). Finally, the last step is an increase of the hydrolysis kinetics thanks to the autocatalysis generated by the carboxylic acid end groups, and mass loss begins when chain fragments are small enough to dissolve in the degradation medium.

All PDMS/polyester elastomers exhibited a linear mass loss which achieved more than 3 wt.\% after 5 weeks of immersion compared to the PDMS reference which did not show significant mass loss (Fig. 11). This linear profile is in contradiction with the mechanisms mentioned above. A slow mass loss is expected during the first week of immersion followed by a mass loss increase with a higher slope. In our case, the mass loss was linear from the beginning indicating a change of behaviour of the polyester segments in a silicone environment.According to the literature, the polymer supposed to hydrolyze the fastest is PLGA, then comes PCL- $b$-PDMS- $b$-PCL and at last PCL which degrades very slowly [24]. In PDMS/polyester networks, this order is not respected. As shown in Fig. 11, PCL-N83/17 exhibited a very similar mass loss trend to PLGA-N88/12 whereas TGO-N73/27 showed a lower hydrolytic degradation rate for each intervals time. These results showed that the polyester segments behave differently when inserted in a silicone matrix. PCL, which was supposed to crystallize in its pure form $\left(\mathrm{X}_{\mathrm{c}}=50 \%\right)$, is not able to

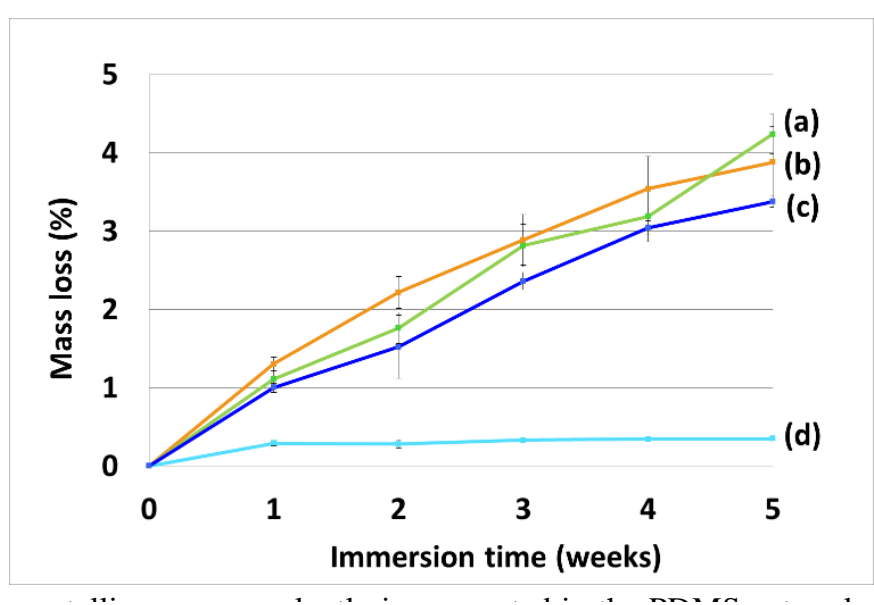

Fig. 11. Mass losses of the different coatings during hydrolytic degradationaccording to DSC analysis. On the contrary, polyester segments in in deionized water for PCL-N83/17 (a), PLGA-N88/12 (b), TGO-N73/27 (c) $\%$ for the pure triblock copolymer). This may explain why the and PDMS (d).

$a$ do not present any crystalline phase, since it is known that water diffusion can be delayed by the presence of crystalline phases in its path [22,35].

This observed degradation could be attributed to bulk or surface degradation. In the literature aliphatic polyesters are well known to undergo bulk degradation [56]. However, the coatings developed in this study are mainly composed of a PDMS network (at least $70 \mathrm{wt} \%$ of PDMS in the dry coatings). If the water diffusion is faster than the polyester bond hydrolysis, the degradation mechanism will be bulk degradation, however, if the diffusion of water is slow, as expected within a hydrophobic PDMS matrix, the degradation mechanism will be a surface degradation [57].

Thus all PDMS/polyester coatings of our study showed a mass loss of 3 to 4 wt. $\%$ after 5 weeks which can be due to the loss of PDMS or polyester oligomer segments. This mass loss is likely due to surface erosion of the coatings rather than bulk degradation due to the high amount of PDMS in the network. The diffusion of water in the coatings will be subject to another forthcoming study to confirm this assumption. 


\section{Conclusions}

We have explored the design of a new surface-active coatings based on PDMS/polyester elastomers which could degrade in water. Three polyester macrocrosslinkers composed of degradable PLGA or PCL chains were covalently incorporated in a condensation-cured PDMS matrix with different polyester segment content $(12,17$ and $20 \mathrm{wt} \%$ relative to the dried coating). PCL- $b$-PDMS- $b$-PCL triblock macrocrosslinker was shown to improve the chemical compatibility between the polyester and the PDMS elastomeric matrix leading to a higher crystallinity of the polyester segments and a higher elastic modulus of the final coating. Among the crosslinked PDMS/polyester networks, TGO-N73/27 is the one that maintains the less the specific properties of FRC such as Fouling Release Coatings as after immersion in water such as low roughness, low elastic modulus, low surface free energy despite its progressive erosion. All PDMS/polyester networks exhibited hydrolytic degradations during immersion in water with [3-4] wt.\% of mass loss after 5 weeks. Moreover, these PDMS/polyester networks could be potentially categorized as ambiguous surfaces as they exhibited a significant chemistry renewal with contact angle hysteresis $\Delta \theta \geq 40^{\circ}$.

The PLGA-N88/12 coating maintained its hydrophobicity during immersion $\left(\theta_{\mathrm{w}, \mathrm{adv}}=92 \pm 4^{\circ}\right)$ compared with the others containing PCL $\left(\theta_{\mathrm{w}, \text { adv }} \leq 80^{\circ}\right)$ after 5 weeks of immersion in water. In addition, its surface free energy remained low whereas. PCL-based coatings tend to exhibit a more polar surface after immersion which an increased surface free energy up to $40 \mathrm{~mJ} / \mathrm{m}^{2}$. Thus, thanks to its slow degradation in water combined with its low roughness, low elastic modulus, low surface energy properties and its ambiguous surface structure, the PLGAN88/12 coating was shown to meet all requirements to be exploited as a new environmentally friendly Fouling Release Coating. 


\section{Funding sources}

This study was financed by the French Ministry of Armies (DGA, Direction Générale de l'Armement).

\section{References}

[1] S. Sonak, P. Pangam, A. Giriyan, K. Hawaldar, Implications of the ban on organotins for protection of global coastal and marine ecology, J. Environ. Manage. 90 (2009) S96-S108. doi:10.1016/j.jenvman.2008.08.017.

[2] Capt. Ahmed Saad Hassan Noufal, Capt. Mohamed Hussein Nassar Hassan, The Impact of Implementing the International Convention on the Control of Harmful Anti-fouling Systems in Ships (AFS Convention) on the Marine Environment, J. Shipp. Ocean Eng. 6 (2016). doi:10.17265/2159-5879/2016.01.007.

[3] M. Lejars, A. Margaillan, C. Bressy, Fouling Release Coatings: A Nontoxic Alternative to Biocidal Antifouling Coatings, Chem. Rev. 112 (2012) 4347-4390. doi:10.1021/cr200350v.

[4] J.A. Batista-Andrade, S.S. Caldas, J.L. de Oliveira Arias, I.B. Castro, G. Fillmann, E.G. Primel, Antifouling booster biocides in coastal waters of Panama: First appraisal in one of the busiest shipping zones, Mar. Pollut. Bull. 112 (2016) $415-419$. doi:10.1016/j.marpolbul.2016.07.045.

[5] F. Faÿ, I. Linossier, D. Carteau, A. Dheilly, A. Silkina, K. Vallée-Réhel, Booster biocides and microfouling, Biofouling. 26 (2010) 787-798. doi:10.1080/08927014.2010.518234.

[6] G. Galli, E. Martinelli, Amphiphilic Polymer Platforms: Surface Engineering of Films for Marine Antibiofouling, Macromol. Rapid Commun. (2017) n/a-n/a. doi:10.1002/marc.201600704.

[7] F. Faÿ, M.L. Hawkins, K. Réhel, M.A. Grunlan, I. Linossier, Non-toxic, anti-fouling silicones with variable PEO-silane amphiphile content, Green Mater. 4 (2016) 53-62. doi:10.1680/jgrma.16.00003.

[8] M.A. Rufin, M.E. Barry, P.A. Adair, M.L. Hawkins, J.E. Raymond, M.A. Grunlan, Protein resistance efficacy of PEO-silane amphiphiles: Dependence on PEO-segment length and concentration, Acta Biomater. 41 (2016) $247-252$. doi:10.1016/j.actbio.2016.04.020.

[9] M.L. Hawkins, M.A. Rufin, J.E. Raymond, M.A. Grunlan, Direct observation of the nanocomplex surface reorganization of antifouling silicones containing a highly mobile PEO-silane amphiphile, J. Mater. Chem. B. 2 (2014) 5689. doi:10.1039/C4TB01008F.

[10] R. Murthy, B.M. Bailey, C. Valentin-Rodriguez, A. Ivanisevic, M.A. Grunlan, Amphiphilic silicones prepared from branched PEOsilanes with siloxane tethers, J. Polym. Sci. Part Polym. Chem. 48 (n.d.) 4108-4119. doi:10.1002/pola.24203.

[11] M.A. Rufin, J.A. Gruetzner, M.J. Hurley, M.L. Hawkins, E.S. Raymond, J.E. Raymond, M.A. Grunlan, Enhancing the protein resistance of silicone via surface-restructuring PEO-silane amphiphiles with variable PEO length, J. Mater. Chem. B. 3 (2015) $2816-$ 2825. doi:10.1039/C4TB02042A.

[12] A. Camós Noguer, S.M. Olsen, S. Hvilsted, S. Kiil, Diffusion of surface-active amphiphiles in silicone-based fouling-release coatings, Prog. Org. Coat. 106 (2017) 77-86. doi:10.1016/j.porgcoat.2017.02.014.

[13] M. Oliva, E. Martinelli, G. Galli, C. Pretti, PDMS-based films containing surface-active amphiphilic block copolymers to combat fouling from barnacles B. amphitrite and B. improvisus, Polymer. 108 (2017) 476-482. doi:10.1016/j.polymer.2016.12.021.

[14] E. Martinelli, M.K. Sarvothaman, M. Alderighi, G. Galli, E. Mielczarski, J.A. Mielczarski, PDMS network blends of amphiphilic acrylic copolymers with poly(ethylene glycol)-fluoroalkyl side chains for fouling-release coatings. I. Chemistry and stability of the film surface, J. Polym. Sci. Part Polym. Chem. 50 (2012) 2677-2686. doi:10.1002/pola.26050.

[15] C.S. Gudipati, C.M. Greenlief, J.A. Johnson, P. Prayongpan, K.L. Wooley, Hyperbranched fluoropolymer and linear poly(ethylene glycol) based amphiphilic crosslinked networks as efficient antifouling coatings: An insight into the surface compositions, topographies, and morphologies, J. Polym. Sci. Part Polym. Chem. 42 (2004) 6193-6208. doi:10.1002/pola.20466.

[16] S. Jiang, H. Xue, S. Chen, Marine coatings, US8349966B2, 2013. https://patents.google.com/patent/US8349966B2/en (accessed July 13, 2018)

[17] X. Zhang, D. Brodus, V. Hollimon, H. Hu, A brief review of recent developments in the designs that prevent bio-fouling on silicon and silicon-based materials, Chem. Cent. J. 11 (2017) 18. doi:10.1186/s13065-017-0246-8.

[18] M.S. Selim, M.A. Shenashen, S.A. El-Safty, S.A. Higazy, M.M. Selim, H. Isago, A. Elmarakbi, Recent progress in marine foulrelease polymeric nanocomposite coatings, Prog. Mater. Sci. 87 (2017) 1-32. doi:10.1016/j.pmatsci.2017.02.001.

[19] U. Eduok, O. Faye, J. Szpunar, Recent developments and applications of protective silicone coatings: A review of PDMS functional materials, Prog. Org. Coat. 111 (2017) 124-163. doi:10.1016/j.porgcoat.2017.05.012.

[20] J.E. Gittens, T.J. Smith, R. Suleiman, R. Akid, Current and emerging environmentally-friendly systems for fouling control in the marine environment, Biotechnol. Adv. 31 (2013) 1738-1753. doi:10.1016/j.biotechadv.2013.09.002.

[21] A.G. Nurioglu, A.C.C. Esteves, G. de With, Non-toxic, non-biocide-release antifouling coatings based on molecular structure design for marine applications, J Mater Chem B. 3 (2015) 6547-6570. doi:10.1039/C5TB00232J.

[22] A. Göpferich, Mechanisms of polymer degradation and erosion, Biomaterials. 17 (1996) 103-114. doi:10.1016/0142-9612(96)857553.

[23] C.G. Pitt, G. Zhong-wei, Modification of the rates of chain cleavage of poly( $\epsilon$-caprolactone) and related polyesters in the solid state, J. Controlled Release. 4 (1987) 283-292. doi:10.1016/0168-3659(87)90020-4.

[24] F. Azemar, F. Faÿ, K. Réhel, I. Linossier, Control of hydration and degradation properties of triblock copolymers polycaprolactone- $b$ -polydimethylsiloxane- $b$-polycaprolactone, J. Appl. Polym. Sci. 131 (2014) n/a-n/a. doi:10.1002/app.40431.

[25] K. Avgoustakis, Polylactic-Co-Glycolic Acid (PLGA), Encycl. Biomater. Biomedic. Eng., (2005) 1-11. doi:10.1081/E-EBBE120013950.

[26] K. Xu, A. Kozluca, E.B. Denkbaş, E. Pişkin, Synthesis of PDLLA homopolymers with different molecular weights, J. Appl. Polym. Sci. 59 (1996) 561-563. doi:10.1002/(SICI)1097-4628(19960118)59:3<561::AID-APP23>3.0.CO;2-V.

[27] J.S. Wiggins, M.K. Hassan, K.A. Mauritz, R.F. Storey, Hydrolytic degradation of poly(d,1-lactide) as a function of end group: Carboxylic acid vs. hydroxyl, Polymer. 47 (2006) 1960-1969. doi:10.1016/j.polymer.2006.01.021. 
[28] S.H. Choi, T.G. Park, Synthesis and characterization of elastic PLGA/PCL/PLGA tri-block copolymers, J. Biomater. Sci. Polym. Ed. 13 (2002) 1163-1173. doi:10.1163/156856202320813864

[29] M.-H. Huang, S. Li, M. Vert, Synthesis and degradation of PLA-PCL-PLA triblock copolymer prepared by successive polymerization of $\varepsilon$-caprolactone and dl-lactide, Polymer. 45 (2004) 8675-8681. doi:10.1016/j.polymer.2004.10.054.

[30] N. Wang, X.S. Wu, C. Li, M.F. Feng, Synthesis, characterization, biodegradation, and drug delivery application of biodegradable lactic/glycolic acid polymers: I. Synthesis and characterization, J. Biomater. Sci. Polym. Ed. 11 (2000) 301-318. doi:10.1163/156856200743715.

[31] F. Nederberg, E.F. Connor, M. Möller, T. Glauser, J.L. Hedrick, New Paradigms for Organic Catalysts: The First Organocatalytic Living Polymerization, Angew. Chem. Int. Ed. 40 (2001) 2712-2715. doi:10.1002/1521-3773(20010716) 40:14<2712::AIDANIE2712>3.0.CO;2-Z.

[32] X. Sun, F. Zhang, Y. Chen, Z. Cheng, Y. Su, J. Hang, L. Jin, N. Li, D. Shang, L. Shi, Preparation and properties of crosslinked network coatings based on perfluoropolyether/poly(dimethyl siloxane)/acrylic polyols for marine fouling-release applications, J. Appl. Polym. Sci. 132 (2015) n/a-n/a. doi:10.1002/app.41860.

[33] J.S. Wiggins, M.K. Hassan, K.A. Mauritz, R.F. Storey, Hydrolytic degradation of poly(d,l-lactide) as a function of end group: Carboxylic acid vs. hydroxyl, Polymer. 47 (2006) 1960-1969. doi:10.1016/j.polymer.2006.01.021.

[34] N. Wang, X.S. Wu, C. Li, M.F. Feng, Synthesis, characterization, biodegradation, and drug delivery application of biodegradable lactic/glycolic acid polymers: I. Synthesis and characterization, J. Biomater. Sci. Polym. Ed. 11 (2000) 301-318. doi:10.1163/156856200743715.

[35] K. Ginjupalli, G.V. Shavi, R.K. Averineni, M. Bhat, N. Udupa, P. Nagaraja Upadhya, Poly( $\alpha$-hydroxy acid) based polymers: A review on material and degradation aspects, Polym. Degrad. Stab. 144 (2017) 520-535. doi:10.1016/j.polymdegradstab.2017.08.024.

[36] C. D'Avila Carvalho Erbetta, Synthesis and Characterization of Poly(D,L-Lactide-co-Glycolide) Copolymer, J. Biomater. Nanobiotechnology. 03 (2012) 208-225. doi:10.4236/jbnb.2012.32027.

[37] S.M. Li, H. Garreau, M. Vert, Structure-property relationships in the case of the degradation of massive aliphatic poly-(?-hydroxy acids) in aqueous media: Part 1: Poly(dl-lactic acid), J. Mater. Sci. Mater. Med. 1 (1990) 123-130. doi:10.1007/BF00700871.

[38] S. Li, H. Garreau, M. Vert, Structure-property relationships in the case of the degradation of massive poly(?-hydroxy acids) in aqueous media: Part 3 Influence of the morphology of poly(l-lactic acid), J. Mater. Sci. Mater. Med. 1 (1990) 198-206. doi:10.1007/BF00701077.

[39] T.G. Park, Degradation of poly(lactic-co-glycolic acid) microspheres: effect of copolymer composition, Biomaterials. 16 (1995) 1123-1130. doi:10.1016/0142-9612(95)93575-X.

[40] B. Bogdanov, V. Toncheva, E. Schacht, L. Finelli, B. Sarti, M. Scandola, Physical properties of poly(ester-urethanes) prepared from different molar mass polycaprolactone-diols, Polymer. 40 (1999) 3171-3182. doi:10.1016/S0032-3861(98)00552-7.

[41] M.V. Pergal, V.V. Antić, M.N. Govedarica, D. Goäevac, S. Ostojić, J. Djonlagić, Synthesis and characterization of novel urethane-siloxane copolymers with a high content of PCL-PDMS-PCL segments, J. Appl. Polym. Sci. 122 (2011) 2715-2730. doi:10.1002/app.33926.

[42] S. Zhou, X. Deng, X. Li, W. Jia, L. Liu, Synthesis and characterization of biodegradable low molecular weight aliphatic polyesters and their use in protein-delivery systems, J. Appl. Polym. Sci. 91 (2004) 1848-1856. doi:10.1002/app.13385.

[43] Z.-Y. Wang, Y.-M. Zhao, F. Wang, J. Wang, Syntheses of poly(lactic acid-co-glycolic acid) serial biodegradable polymer materials via direct melt polycondensation and their characterization, J. Appl. Polym. Sci. 99 (2006) 244-252. doi:10.1002/app.22468.

[44] E. Johnston, S. Bullock, J. Uilk, P. Gatenholm, K.J. Wynne, Networks from $\alpha, \omega$-Dihydroxypoly(dimethylsiloxane) and (Tridecafluoro-1,1,2,2-tetrahydrooctyl)triethoxysilane: Surface Microstructures and Surface Characterization, Macromolecules. 32 (1999) 8173-8182. doi:10.1021/ma990628y.

[45] T. Ogoshi, T. Fujiwara, M. Bertolucci, G. Galli, E. Chiellini, Y. Chujo, K.J. Wynne, Tapping Mode AFM Evidence for an Amorphous Reticular Phase in a Condensation-Cured Hybrid Elastomer: $\alpha, \omega$-Dihydroxypoly(dimethylsiloxane)/Poly(diethoxysiloxane)/Fumed Silica Nanoparticles, J. Am. Chem. Soc. 126 (2004) 12284-12285. doi:10.1021/ja0474345.

[46] K.J. Wynne, T. Ho, E.E. Johnston, S.A. Myers, Surface science and stability of networks prepared from hydroxy-terminated polydimethylsiloxane and methyltriethoxysilane, Appl. Organomet. Chem. 12 (1998) 763-770. doi:10.1002/(SICI)10990739(199810/11)12:10/11<763::AID-AOC784>3.0.CO;2-C.

[47] M. Berglin, K.J. Wynne, P. Gatenholm, Fouling-release coatings prepared from $\alpha, \omega$-dihydroxypoly(dimethylsiloxane) cross-linked with (heptadecafluoro-1,1,2,2-tetrahydrodecyl)triethoxysilane, J. Colloid Interface Sci. 257 (2003) 383-391. doi:10.1016/S00219797(02)00037-1.

[48] T.H. Duong, J.-F. Briand, A. Margaillan, C. Bressy, Polysiloxane-Based Block Copolymers with Marine Bacterial Anti-Adhesion Properties, ACS Appl. Mater. Interfaces. 7 (2015) 15578-15586. doi:10.1021/acsami.5b04234.

[49] T.H. Duong, J.-F. Briand, A. Margaillan, C. Bressy, Polysiloxane-Based Block Copolymers with Marine Bacterial Anti-Adhesion Properties, ACS Appl. Mater. Interfaces. 7 (2015) 15578-15586. doi:10.1021/acsami.5b04234.

[50] J.Y. Park, D. Ahn, Y.Y. Choi, C.M. Hwang, S. Takayama, S.H. Lee, S.-H. Lee, Surface chemistry modification of PDMS elastomers with boiling water improves cellular adhesion, Sens. Actuators B Chem. 173 (2012) 765-771. doi:10.1016/j.snb.2012.06.096.

[51] M.E.R. Shanahan, A simple analysis of local wetting hysteresis on a Wilhelmy plate, Surf. Interface Anal. 17 (1991) $489-495$. doi:10.1002/sia.740170713.

[52] J.-M.D. Meglio, Contact Angle Hysteresis and Interacting Surface Defects, Europhys. Lett. EPL. 17 (1992) 607-612. doi:10.1209/0295-5075/17/7/006.

[53] M.I. Aranguren, Crystallization of polydimethylsiloxane: effect of silica filler and curing, Polymer. 39 (1998) 4897-4903. doi:10.1016/S0032-3861(97)10252-X.

[54] S. Venkatraman, N. Davar, A. Chester, L. Kleiner, An Overview of Controlled Release Systems, Handb. Pharm. Controlled Release Technol., D.L. Wise (Ed.), 2000, pp. 431-463.

[55] M. Vert, Lactic Acid-based Degradable Polymers, Handb. Biodegrad. Polym., C. Bastioli (Ed.), 2014, pp. 301-320.

[56] F. Faÿ, I. Linossier, V. Langlois, E. Renard, K. Vallée-Réhel, Degradation and Controlled Release Behavior of $\varepsilon$-Caprolactone Copolymers in Biodegradable Antifouling Coatings, Biomacromolecules. 7 (2006) 851-857. doi:10.1021/bm0509669. 
[57] C. Bressy, M.N. NGuyen, B. Tanguy, V.G. Ngo, A. Margaillan, Poly(trialkylsilyl methacrylate)s: A family of hydrolysable polymers with tuneable erosion profiles, Polym. Degrad. Stab. 95 (2010) 1260-1268. doi:10.1016/j.polymdegradstab.2010.03.017. 